\title{
Expression of E-cadherin, P-cadherin and $\beta$-catenin in canine malignant mammary tumours in relation to clinicopathological parameters, proliferation and survival
}

\author{
Adelina Gama a , Joana Paredes ${ }^{\text {b,c }}$, Fátima Gärtner ${ }^{\text {b,d }}$, Anabela Alves ${ }^{\text {a }}$, \\ Fernando Schmitt ${ }^{\text {b,c,e,* }}$ \\ a Department of Veterinary Sciences, University of Trás-os-Montes and Alto Douro (UTAD), 5001-911 Vila Real, Portugal \\ ${ }^{\mathrm{b}}$ Institute of Molecular Pathology and Immunology of the University of Porto (IPATIMUP), 4200-465 Porto, Portugal \\ ${ }^{\mathrm{c}}$ Life and Health Science Research Institute (ICVS), Health Science School, University of Minho, Braga, Portugal \\ ${ }^{\mathrm{d}}$ Instituto de Ciências Biomédicas de Abel Salazar, University of Porto, 4099-003 Porto, Portugal \\ e Medical Faculty, University of Porto, Porto, Portugal
}

Accepted 27 May 2007

\begin{abstract}
Cadherin-catenin complexes play a critical role in intercellular adhesion, and their altered expression has been implicated in tumour progression. In this study, the expression of E-cadherin, P-cadherin and $\beta$-catenin was analysed in 65 canine malignant mammary tumours and correlated with clinicopathological parameters, proliferation and survival. Reduction in E-cadherin expression was significantly associated with increased tumour size, high histological and invasion grades, lymph node metastasis and high mitotic index. Reduced $\beta$-catenin expression was associated with high histological and invasion grades. Anomalous expression of P-cadherin was only associated with invasion. In 39 cases for which follow-up data were available, reduced E-cadherin and $\beta$-catenin expression was significantly associated with shorter overall survival and disease free survival. Abnormal expression of adhesion molecules is a common phenomenon in canine mammary malignant tumours and may play a central role in tumour progression.
\end{abstract}

(c) 2007 Elsevier Ltd. All rights reserved.

Keywords: Canine; Mammary tumours; E-cadherin; P-cadherin; $\beta$-Catenin

\section{Introduction}

Cadherins are calcium-dependent cell-cell adhesion molecules that play critical roles during embryogenesis and in the maintenance of normal adult tissue architecture (Takeichi, 1991; Gumbiner, 1996). Cadherins interact with several proteins termed catenins, including $\alpha-, \beta$ - and $\gamma$ catenin, which link cadherins to the actin cytoskeleton and mediate signal-transduction mechanisms that control

\footnotetext{
${ }^{*}$ Corresponding author. Address: Institute of Molecular Pathology and Immunology of the University of Porto (IPATIMUP), 4200-465 Porto, Portugal. Tel.: +351 22 5570700; fax: +351 225570799 .

E-mail address: fernando.schmitt@ipatimup.pt (F. Schmitt).
}

cellular events, including cell polarity, differentiation, growth and migration (Knudsen et al., 1998).

The best characterised and most widely distributed members of the family are the classical cadherins, namely epithelial (E-) and placental (P-) cadherins (Nose and Takeichi, 1986). E-cadherin is found in almost all human epithelial tissues, whereas P-cadherin is restricted to the basal layers of stratified epithelium (Nose and Takeichi, 1986; Shimoyama et al., 1989). In normal human breast and canine mammary tissue, these molecules show a distinct pattern of expression; E-cadherin is expressed by luminal epithelial cells, whereas expression of P-cadherin is restricted to myoepithelial cells (Shimoyama et al., 1989; Palacios et al., 1995; Gama et al., 2002, 2004). 
Loss or down-regulation of E-cadherin/ $\beta$-catenin complexes is associated with oncogenic progression in human breast cancer (Gamallo et al., 1993; Yoshida et al., 2001). In addition, anomalous epithelial expression of P-cadherin in human breast cancer is associated with aggressive biological behaviour and poor outcome (Palacios et al., 1995; Peralta Soler et al., 1999; Paredes et al., 2002, 2005).

The role of cadherins and catenins in canine mammary tumours is still poorly understood (Restucci et al., 1997; Reis et al., 2003; Brunetti et al., 2005; De Matos et al., 2007). Brunetti et al. (2005) showed that reduced E-cadherin/ $\beta$-catenin expression influences invasion of canine mammary tumours, but not proliferation or survival. Loss of E-cadherin in canine mammary tumours was correlated with tumour size, ulceration, lymph node metastasis, necrosis and infiltrative growth (Matos et al., 2006). Recently, we found a significant association between Pcadherin expression in canine mammary tumours and histological type (Gama et al., 2004). In the present study, we correlated the expression of E- and P-cadherin and $\beta$ catenin in a series of malignant canine mammary tumours with clinicopathological parameters, proliferation and survival to study their possible role in canine mammary tumorigenesis.

\section{Materials and methods}

\section{Source of tumours}

Sixty-five malignant canine mammary tumours were selected from the histopathological files of the University of Trás-os-Montes and Alto Douro, Vila Real and from the Institute of Biomedical Science at the University of Porto, Portugal. The material had been fixed in $10 \%$ neutral buffered formalin and embedded in paraffin wax. Sections $(3 \mu \mathrm{m})$ were cut and stained with haematoxylin and eosin (HE) for histological examination and immunohistochemistry.

\section{Case follow-up}

Follow-up data were available for 39 cases for a mean of 15 months (range 1-36 months) after surgical treatment. Disease-free survival (DFS) and overall survival (OS) were calculated from the day of the surgery until the time of recurrence/metastasis or death, respectively. The cause of death was confirmed at post-mortem examination.

\section{Histopathological examination}

Tumours were classified according to the World Health Organization (WHO) criteria for canine mammary neoplasms (Misdorp et al., 1999) by three pathologists. Each tumour was assessed for size, skin ulceration, necrosis and mode of growth (expansile vs. infiltrative). Regional lymph nodes were available in 52 cases and assessed for the presence of metastases.

Malignant epithelial neoplasms were graded according to the Nottingham method for human breast tumours (Elston and Ellis, 1998). Tubule formation, nuclear pleomorphism and mitotic index were scored on a scale of 1-3 (slight, moderate or marked degree) and grades were based on the total score: grade I (well differentiated): 3-5 points; grade II (moderately differentiated): 6-7 points; and grade III (poorly differentiated): 8-9 points. Tumours were also graded for invasion according to Gilbertson et al. (1983): stage 0 (non-infiltrating); stage I (stromal inva- sion); and stage II (neoplastic emboli in vessels and/or lymph node involvement).

\section{Immunohistochemistry}

Monoclonal antibodies used in the present study were anti-E-cadherin (4A2C7, 1:100, Zymed Laboratory), anti-P-cadherin (clone 56, 1:50, BD Transduction Laboratories), anti- $\beta$-catenin (CAT-5H10, 1:100, Zymed Laboratory) and anti-Ki-67 (MIB-1, 1:50, Dakocytomation). A streptavidin-biotin-peroxidase complex method was used with a commercial detection system (Ultra Vision Detection System, Lab Vision Corporation) following the manufacturer's instructions.

Antigen retrieval for E-cadherin and $\beta$-catenin was carried out by microwave treatment in a $0.05 \%$ detergent solution (Extran, Merck) and for P-cadherin with ethylene diamine tetraacetic acid (EDTA) buffer $\mathrm{pH}$ 8.0 (Lab Vision Corporation) in a boiling water bath for $20 \mathrm{~min}$. For Ki67 antigen retrieval, slides were incubated with $0.2 \mathrm{mg} / \mathrm{mL}$ trypsin (Merck) in phosphate buffered saline (PBS) for $10 \mathrm{~min}$ at $37^{\circ} \mathrm{C}$ prior to microwave treatment $(3 \times 5 \mathrm{~min})$ in $10 \mathrm{mM}$ citrate buffer, $\mathrm{pH} 6.0$. Adjacent normal mammary tissues were used as internal positive controls. The primary antibody was replaced with PBS for negative controls.

\section{Quantification of immunolabelling}

P-cadherin expression in canine mammary tissues was assessed semiquantitatively according to the percentage of immunoreactive cells (cells showing a membranous and/or cytoplasmic expression pattern) in negative $(0:<10 \%)$ and positive $(1: 10-25 \% ; 2: 26-50 \% ; 3:>50 \%)$ tumours (Gama et al., 2004). E-cadherin and $\beta$-catenin immunoreactivity was classified as membranous (localised at cell-cell boundaries) or cytoplasmic (uniformly distributed through the cytoplasm, with no recognisable distinction between membrane and cytoplasm). Nuclear expression of $\beta$ catenin was only detected in normal mammary gland epithelial cells adjacent to the tumour in two cases and therefore was not scored. Cases were grouped according to Brunetti et al. (2005) as "preserved", when positivity was membranous and higher than $75 \%$ of neoplastic epithelial cells and as "reduced" in all remaining samples, including negative tumours.

Combined variables were created for immunoreactivity patterns of $\mathrm{E}$ cadherin/ $\beta$-catenin (E-cad/ $\beta$-cat), E-cadherin/P-cadherin (E-cad/P-cad) and $\beta$-catenin $/ \mathrm{P}$-cadherin $(\beta$-cat $/ \mathrm{P}$-cad) to investigate a possible relationship between any reduction/lack of expression of E-cadherin/ $\beta$-catenin and over-expression of P-cadherin. Tumours were classified into four categories $(+/+,+/-,-/+,-/-)$ for each combined variable.

\section{Proliferative indices}

Mitotic index and Ki-67 index were determined by counting 1000 neoplastic cells in the most mitotically active areas or areas with the highest Ki-67 positivity and were calculated as the percentage of tumour cells that exhibited mitotic figures or had positive staining for Ki-67, respectively.

\section{Statistical analysis}

For statistical analysis, associations between the expression of the different adhesion molecules and continuous variables (mitotic and $\mathrm{Ki}-67$ indices) were assessed by analysis of variance (ANOVA). Associations between adhesion molecule expression and clinicopathological parameters (categorical variables), such as tumour size, histological type, histological grade and invasion, were performed using the $\chi^{2}$ test. Fisher's exact test was performed when compared variables had exactly two groups $(2 \times 2$ table $)$, such as E-cadherin expression (preserved and reduced groups) versus ulceration (absent and present groups). Survival curves were generated by the Kaplan-Meyer method and the survival rates were compared using the log-rank test. All statistical analysis was performed using SPSS 11.5 statistical software. $P$ values $<0.05$ were considered statistically significant. 


\section{Results}

The 65 malignant tumours examined in this study were classified as solid carcinomas (22 cases), tubulopapillary carcinomas (12), complex carcinomas (12), carcinosarcomas (12), spindle cell carcinomas (four) and sarcomas (three) according to WHO criteria. Epithelial tumours were classified as grade I (four cases), grade II (18) and grade III (40) according to the Nottingham method.

Expression of P-cadherin was evident in all histological types, whereas expression of E-cadherin and $\beta$-catenin was negative in all sarcomas. Reduction/lack of E-cadherin expression was evident in 27 malignant tumours (41.5\%) and reduction/lack of $\beta$-catenin expression in 35 (53.8\%). Aberrant cytoplasmic/membranous expression of P-cadherin was found in $56(86.2 \%)$ malignant tumours. In 13 $(20 \%)$ of these 56 tumours, $10-25 \%$ of neoplastic cells were positive; in $17(26.2 \%), 26-50 \%$ were positive; and in 26 $(40 \%)>50 \%$ were positive (Fig. 1).

Immunohistochemical expression of E-cadherin and $\beta$ catenin was significantly correlated $(P<0.0001)$ : 26 cases were positive for both proteins, there was reduced expression of both proteins in 23 cases and 16 cases were discordant. We found no significant association between aberrant $\mathrm{P}$-cadherin expression and reduced E-cadherin or $\beta$-catenin expression.

The relationship between cadherins and $\beta$-catenin expression and several clinicopathological variables is shown in Table 1. There was a significant difference across histological types in expression of E-cadherin $(P=0.01)$. Reduced E-cadherin expression was significantly related to infiltrative tumour growth $(P=0.02)$, higher histological grade $(P<0.0001)$, higher degree of invasion $(P=0.002)$ and lymph node metastasis $(P=0.047)$. Reduced $\beta$-catenin
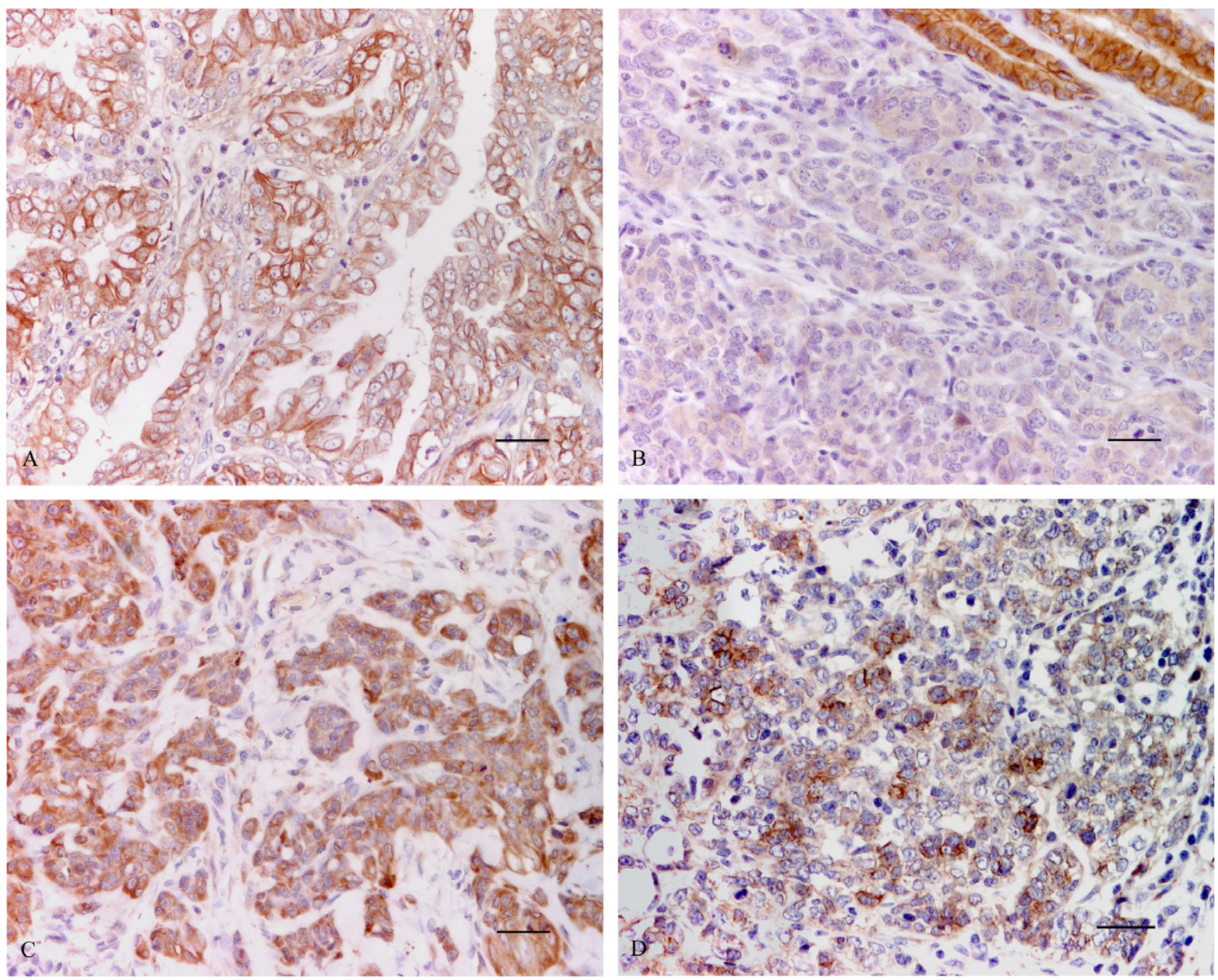

Fig. 1. Immunohistochemical expression of adhesion molecules in malignant canine mammary tumours. (A) Tubulopapillary carcinoma with preserved membranous E-cadherin expression. (B) Solid carcinoma. Neoplastic cells are negative for E-cadherin expression, whereas non-neoplastic epithelial cells are positive. (C) Solid carcinoma, with strong P-cadherin immunoreactivity. (D) Complex carcinoma showing reduced membranous $\beta$-catenin expression $(\operatorname{Bar}=30 \mu \mathrm{m})$. 
Table 1

Association between E-cadherin, P-cadherin and $\beta$-catenin expression and clinicopathological parameters

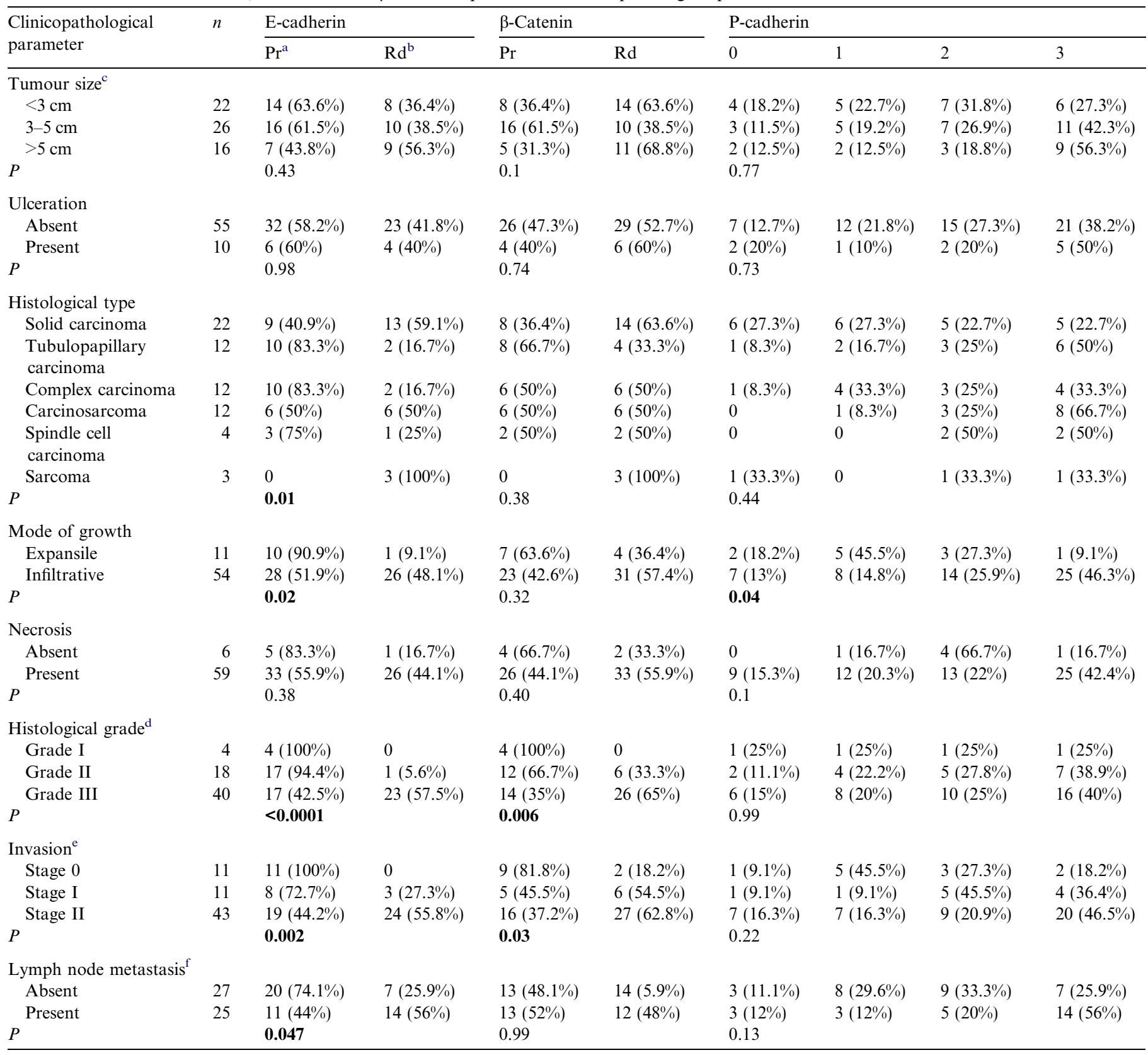

Probability $(P)$ values in bold are significant.

a Preserved.

${ }^{\mathrm{b}}$ Reduced.

c Tumour size was available in 64 cases.

d According to the Nottingham method for human breast tumours (Elston and Ellis, 1998).

${ }^{\mathrm{e}}$ According to Gilbertson et al. (1983).

${ }^{\mathrm{f}}$ Lymph nodes were available in 52 cases.

expression was also associated with high histological grade $(P=0.006)$ and degree of invasion $(P=0.03)$. Anomalous expression of $\mathrm{P}$-cadherin was associated only with invasion $(P=0.04)$.

When proliferation indices (mitotic index and $\mathrm{Ki}-67$ index) were compared with expression patterns of the cadherins and $\beta$-catenin, there were significant differences only between higher mitotic counts and reduced expression of
E-cadherin $(P=0.03)$ and $\beta$-catenin $(P=0.003)$ (Table $2)$. No significant differences were found between P-cadherin groups.

Tumours with reduced expression of E-cadherin and $\beta$ catenin were associated with significantly shorter survival times for both DFS (E-cadherin: $P=0.0263 ; \beta$-catenin: $P=0.0095$ ) and $\mathrm{OS}$ (E-cadherin: $P=0.0245 ; \beta$-catenin: $P=0.0113$ ) (Fig. 2). There was no significant association 
Table 2

Association between E-cadherin, P-cadherin and $\beta$-catenin expression and proliferation indices

\begin{tabular}{|c|c|c|c|}
\hline & \multirow[t]{2}{*}{$n$} & \multirow{2}{*}{$\begin{array}{l}\text { Mitotic index } \\
\begin{array}{l}\text { Mean } \pm \text { standard } \\
\text { deviation }\end{array}\end{array}$} & \multirow{2}{*}{$\begin{array}{l}\text { Ki-67 index } \\
\text { Mean } \pm \text { standard } \\
\text { deviation }\end{array}$} \\
\hline & & & \\
\hline \multicolumn{4}{|l|}{ E-cadherin } \\
\hline Preserved & 33 & $0.88 \pm 0.58$ & $24.98 \pm 9.84$ \\
\hline Reduced & 27 & $1.27 \pm 0.75$ & $29.69 \pm 9.31$ \\
\hline$P$ & & 0.03 & 0.064 \\
\hline \multicolumn{4}{|l|}{$\beta$-Catenin } \\
\hline Preserved & 25 & $0.75 \pm 0.49$ & $24.54 \pm 10.59$ \\
\hline Reduced & 35 & $1.27 \pm 0.49$ & $28.92 \pm 8.93$ \\
\hline$P$ & & 0.003 & 0.088 \\
\hline \multicolumn{4}{|l|}{ P-cadherin } \\
\hline$<10 \%$ & 8 & $1.45 \pm 0.84$ & $26.85 \pm 8.75$ \\
\hline $10-25 \%$ & 12 & $0.76 \pm 0.42$ & $24.1 \pm 7.52$ \\
\hline $26-50 \%$ & 15 & $1.02 \pm 0.68$ & $27.97 \pm 9.93$ \\
\hline$>50 \%$ & 25 & $1.09 \pm 0.72$ & $28.09 \pm 11.18$ \\
\hline$P$ & & 0.179 & 0.693 \\
\hline
\end{tabular}

Probability $(P)$ values in bold are significant. between increased expression of P-cadherin and DFS or OS (Fig. 3).

When tumours were grouped according to combined patterns of expression of E-cadherin/P-cadherin, $\beta$-catenin/P-cadherin and E-cadherin/ $\beta$-catenin, there were significant differences in histological grade III $(P=0.005)$, invasion grades I and II $(P=0.045)$ and lymph node metastasis $(P=0.029)$ for E-cad/P-cad $(-/+)$ cases, but no significant differences for E-cad/P-cad $(+/-)$ or E-cad/ P-cad $(+/+)$ tumours (Supplementary Table 1). There was a significant association between $\beta$-cat/P-cad $(-/+)$ immunoreactivity and less differentiated tumours $(P=$ $0.016)$ when compared to other groups (Supplementary Table 2). Loss/reduction of immunoreactivity for E-cadherin, $\beta$-catenin, or both, was significantly associated with less differentiated tumours $(P=0.003)$, higher invasive grade $(P=0.02)$ and lymph node metastases $(P=0.043)$ (Supplementary Table 3). No statistical differences were found with the remaining variables.
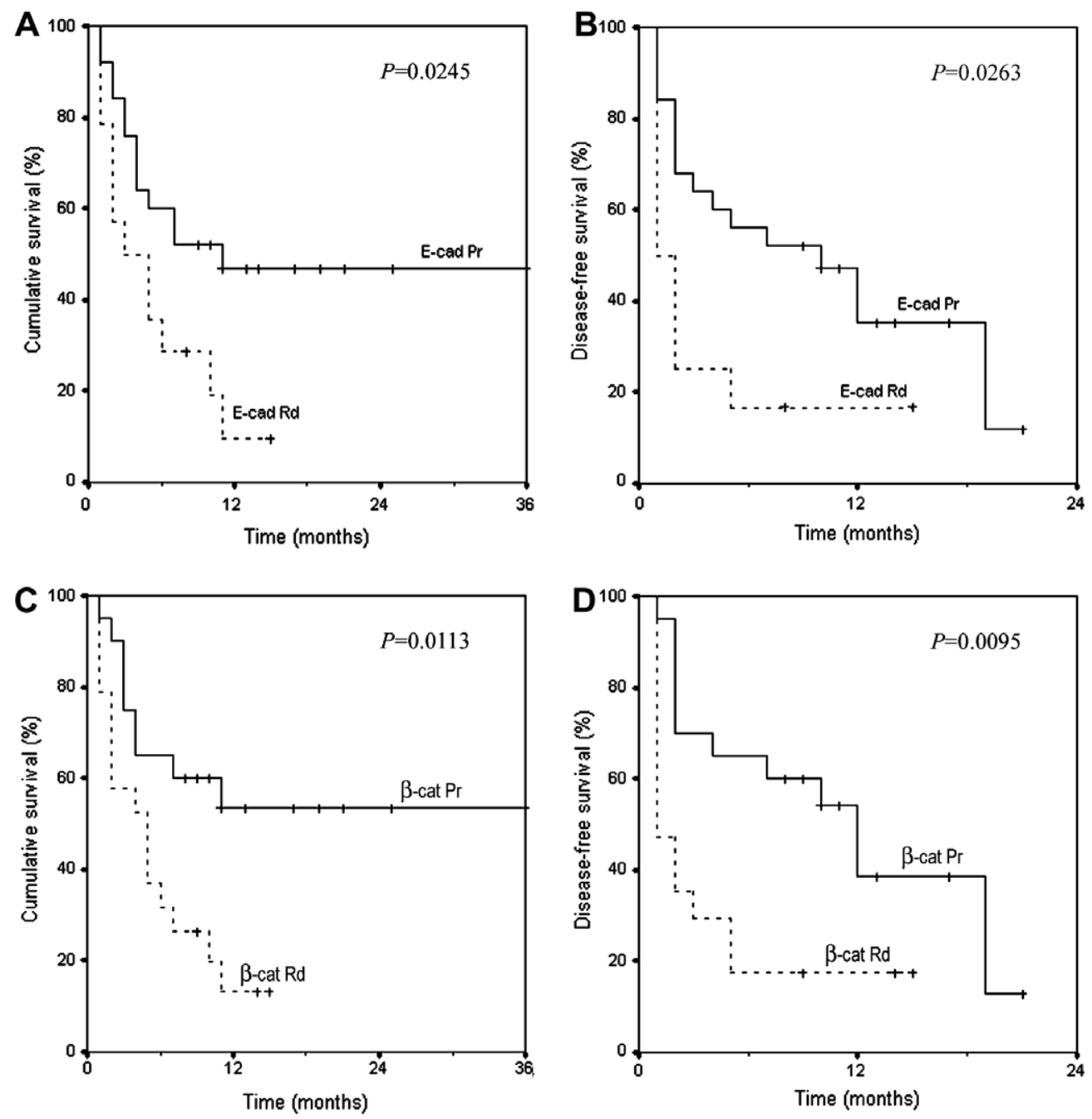

Fig. 2. Kaplan-Meier overall survival and disease-free survival curves of groups with preserved and reduced expression of E-cadherin (A, B) and $\beta$-catenin (C, D). 

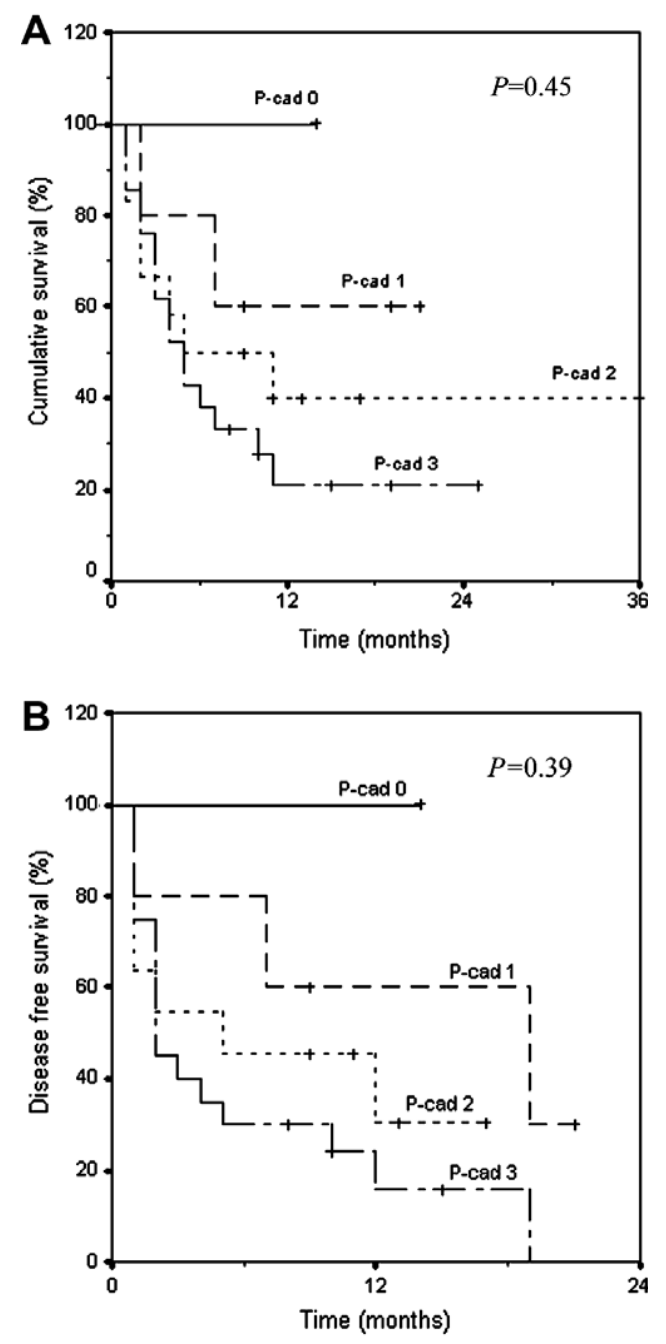

Fig. 3. Kaplan-Meier overall survival (A) and disease-free survival (B) curves of cases with $<10 \%(0), 10-25 \%$ (1), $25-50 \%$ (2) or $>50 \%$ (3) Pcadherin positive cells.

\section{Discussion}

Altered expression or absence of expression of the cadherin-catenin complex results in decreased adhesion of cells and has been implicated in tumorigenesis, particularly tumour cell invasion (Wijnhoven et al., 2000). Several previous reports have described the expression of cadherins and/or associated proteins in canine mammary gland tumours, but the patterns of expression of E-cadherin, Pcadherin and $\beta$-catenin have not been correlated with a wide range of clinicopathological features, including survival (Restucci et al., 1997; Reis et al., 2003; Gama et al., 2004; Brunetti et al., 2005; De Matos et al., 2007).

The present study demonstrated reduced membranous expression of E-cadherin and $\beta$-catenin in malignant canine mammary tumours compared to the normal mammary gland, suggesting that down-regulation of these molecules is a common event in canine mammary tumours. This finding is supported by other recent studies on canine mammary tumours (Brunetti et al., 2005; De Matos et al.,
2007) and human breast cancer (Park et al., 2007). Although P-cadherin is not expressed in normal mammary epithelial cells, a subset of canine mammary tumours exhibited aberrant P-cadherin expression, as previously reported (Gama et al., 2004).

A relationship between E-cadherin and $\beta$-catenin expression was observed in canine mammary tumours in this study, corroborating previous reports of co-expression of these adhesion molecules in canine mammary tissue (Brunetti et al., 2005; De Matos et al., 2007) and human breast tissue (Gillet et al., 2001; Yoshida et al., 2001). This finding is consistent with the formation of adhesion complexes on the cell membrane. Some human breast cancer studies have reported an inverse correlation between loss of E-cadherin and aberrant P-cadherin immunoreactivity (Palacios et al., 1995; Peralta Soler et al., 1999; Gamallo et al., 2001), whereas we found no association between Pcadherin and other adhesion molecules.

In this study, reduced membranous expression of E-cadherin was significantly associated with histological type, poor differentiation, high invasiveness, high index of proliferation and lymph node metastasis. Previous studies on canine mammary tumours have made similar observations (Restucci et al., 1997; Reis et al., 2003; Brunetti et al., 2005; De Matos et al., 2007). Together with our results, this suggests a possible role for E-cadherin-mediated adhesion in preventing invasion and metastasis in canine mammary tumours, corroborating some studies in human breast cancer (Bankfalvi et al., 1999; Madhavan et al., 2001).

However, other studies on human breast cancer have not confirmed such a relationship (Palacios et al., 1995; Bukholm et al., 1998; Kovacs et al., 2003) or have associated preservation of expression of E-cadherin with lymph node metastasis (Gillet et al., 2001; Howard et al., 2005). In contrast to the present study, one previous report on canine mammary tumours showed no association between reduced E-cadherin expression and high histological grade (Matos et al., 2006). Our study identified an association between expression of E-cadherin and mitotic index, whereas no such association was identified by Brunetti et al. (2005). In human cancer studies, we also find opposing results for differentiation (Siitonen et al., 1996; Kovacs et al., 2003; Howard et al., 2005) and proliferation (Charpin et al., 1999; Fricke et al., 2003). Sample selection (histological type, stage, tumour grade), number of cases analysed and differences in staining evaluation may individually or in combination be held responsible for the observed discrepancies between different studies.

Reduced membranous $\beta$-catenin expression was found to be significantly associated with high grade and highly invasive tumours. These findings confirm a previous study (Brunetti et al., 2005) but contradict another (De Matos et al., 2007). In the present study, we found no association between the loss of $\beta$-catenin expression and the presence of lymph node metastases, which supports similar findings in canine (De Matos et al., 2007) and human studies (Bukholm et al., 1998; Gonzalez et al., 1999; Yoshida et al., 
2001), but we did observe a significant association between $\beta$-catenin reduction and high mitotic index, in contrast to a previous study in dogs (Brunetti et al., 2005).

The prognostic significance of E-cadherin and $\beta$-catenin expression in terms of survival of dogs with mammary carcinoma is unclear. Our data show that loss/reduction of E-cadherin and $\beta$-catenin expression is significantly associated with shorter OS and DFS, in contrast to previous findings by Brunetti et al. (2005). In human breast cancer studies, assessment of down-regulation of E-cadherin and catenins as prognostic markers of breast carcinoma has also proven problematic. Some authors claim that Ecadherin and $\beta$-catenin represent valuable prognostic markers (Siitonen et al., 1996; Dollet-Filhard et al., 2006; Park et al., 2007), whereas others have found no association between these molecules and survival time (Peralta Soler et al., 1999; Yoshida et al., 2001).

These conflicting results may reflect the current poor understanding of the dynamics of cell-cell adhesion. This process seems to be regulated at various levels, including gene transcription, protein stability and post-translational modification of the cadherin/catenin complex, in particular by phosphorylation of $\beta$-catenin. Besides its function in establishing tight cell adhesion, $\beta$-catenin plays a major role in cell signalling through interactions with receptor tyrosine kinases and transcription factors of the Lef/Tcf family, suggesting a dual role as a tumour suppressor and as an oncogene in human cancers (Wijnhoven et al., 2000).

Aberrant expression of P-cadherin was associated with invasion, but not with a higher invasion grade, which also takes into account vessel and/or lymph node involvement. Our results with canine mammary malignant tumours do not reflect some in vitro studies in human breast (Paredes et al., 2004) and pancreatic (Taniuchi et al., 2005) cancer cell lines, which suggest a proinvasive role for P-cadherin, through its interaction with signalling molecules such as p120 $0^{\mathrm{ctn}}$ (Taniuchi et al., 2005).

In the present series, we did not find further associations between P-cadherin expressions and other clinicopathological variables or proliferation labelling indices. In our previous study, we described an association with tumour type (Gama et al., 2004), which was not confirmed in this larger series. In human cancer studies we also find contradictory results, probably related with sample selection. Paredes et al. (2005) found no significant correlation with histological type, although some authors suggested that P-cadherin was related with some special tumour types, such as medullary and metaplastic carcinomas (Palacios et al., 1995).

The present work supports our previous study, which did not find a statistically significant difference between P-cadherin aberrant expression and differentiation grade (Gama et al., 2004). However, in recent studies on human breast cancer, P-cadherin expression was significantly associated with increased histological grade (Palacios et al., 1995; Peralta Soler et al., 1999; Gamallo et al., 2001; Paredes et al., 2002, 2005; Kovacs et al., 2003). The small num- ber of grade I tumours in our study may not have provided sufficient statistical power to establish an association.

Some human breast cancer studies (Palacios et al., 1995; Kovacs et al., 2003; Paredes et al., 2005) also failed to find a correlation between anomalous expression of P-cadherin and the presence of lymph node metastases. However, other studies have described an association with highly proliferative tumours (Paredes et al., 2005), lymph node metastases (Gamallo et al., 2001) and poor prognosis (Peralta Soler et al., 1999; Gamallo et al., 2001; Paredes et al., 2005). Although several authors suggested a possible role for P-cadherin in promoting aggressive tumour cell behaviour (Peralta Soler et al., 1999; Gamallo et al., 2001; Paredes et al., 2002, 2005), the biological significance of the anomalous P-cadherin in breast cancer is still poorly understood. As P-cadherin is expressed only by myoepithelial cells in normal breast tissue, the presence of this molecule might indicate a basal/myoepithelial differentiation (Peralta Soler et al., 1999), which has been associated with a poor outcome in human breast cancer (van de Rijn et al., 2002).

Despite some similarities with human breast cancer, canine mammary tumours are frequently associated with myoepithelial differentiation (Misdorp, 2002), which might explain the high percentage of $\mathrm{P}$-cadherin positive tumours in our series. Although no correlation was found in the present study, we propose additional studies including a large series of simple carcinomas in order to investigate if P-cadherin expression is able to identify a subset of carcinomas with a particularly poor prognosis.

It is important to note that alterations in any component may lead to disrupted function of adhesion complexes. When we studied E-cadherin/ $\beta$-catenin combinations, we found that the loss or reduction of at least one of these molecules was associated with less differentiated, highly invasive tumours, frequently with lymph node metastasis, supporting previous canine (Brunetti et al., 2005) and human studies (Bukholm et al., 1998; Wijnhoven et al., 2000). However, future studies are needed with a larger series and a longer follow up to investigate these interrelationships and correlate them with distinct tumour behaviours in the canine mammary gland.

\section{Conclusions}

The study has demonstrated altered expression of intercellular adhesion molecules in canine mammary malignant tumours. There were significant associations between reduced E-cadherin expression and some known prognostic parameters, such as tumour type, histological grade, invasiveness and lymph node metastasis and between reduced $\beta$-catenin expression and histological grade and invasiveness. Preserved expression of these molecules was associated with tumours of low mitotic index and with a better clinical outcome. We were also able to confirm aberrant P-cadherin expression in malignant mammary tumours, 
which was associated with an infiltrative tumour growth, but with no relation to other clinicopathological variables.

\section{Acknowledgements}

The authors thank Mrs Lígia Bento for expert technical assistance. This work was supported by the Centro de Ciência Animal e Veterinária (CECAV) - University of Trás os Montes e Alto Douro (UTAD), Vila Real, Portugal and by Portuguese Science and Technology Foundation, Project POCTI/CVT/57795/2004.

\section{Appendix A. Supplementary data}

Supplementary data associated with this article can be found, in the online version, at doi:10.1016/j.tvjl.2007. 05.024 .

\section{References}

Bankfalvi, A., Terpe, H.J., Breukelmann, D., Bier, B., Rempe, D., Pschadka, G., Krech, R., Lelle, R.J., Boecker, W., 1999. Immunophenotypic and prognostic analysis of E-cadherin and $\beta$-catenin expression during breast carcinogenesis and tumour progression: a comparative study with CD44. Histopathology 34, 25-34.

Brunetti, B., Sarli, G., Preziosi, R., Monari, I., Benazzi, C., 2005. Ecadherin and $\beta$-catenin reduction influence invasion but not proliferation in canine malignant mammary tumors. Veterinary Pathology 42 , 781-787.

Bukholm, I.K., Nesland, J.M., Karesen, R., Jacobsen, U., Borresen-Dale, A.L., 1998. E-cadherin and $\alpha$-, $\beta$-, and $\gamma$-catenin protein expression in relation to metastasis in human breast carcinoma. Journal of Pathology $185,262-266$.

Charpin, C., Bonnier, P., Garcia, S., Andrac, L., Crebassa, B., Dorel, M., Lavaut, M.N., Allasia, C., 1999. E-cadherin and $\beta$-catenin expression in breast medullary carcinomas. International Journal of Oncology 15, 285-292.

De Matos, A.J., Lopes, C.C., Faustino, A.M., Carvalheira, J.G., Rutteman, G.R., Gärtner Mde, F., 2007. E-cadherin, ß-catenin, invasion and lymph node metastases in canine malignant mammary tumours. Acta Pathologica, Microbiologica et Immunologica Scandinavica $115,327-334$.

Dollet-Filhard, M., McCabe, A., Giltnane, J., Cregger, M., Cam, R.L., Rimm, D.L., 2006. Quantitative in situ analysis of $\beta$-catenin expression in breast cancer shows decreased expression is associated with poor outcome. Cancer Research 66, 5487-5494.

Elston, C.W., Ellis, I.O., 1998. Assessment of histological grade. In: Elston, C.W., Ellis, I.O. (Eds.), Systemic Pathology. The Breast., third ed. Churchill Livingstone, London, UK, pp. 365-384.

Fricke, E., Keller, G., Becker, I., Rosivatz, E., Schott, C., Plaschke, S., Rudelius, M., Hermannstadter, C., Busch, R., Hofler, H., Becker, K.F., Luber, B., 2003. Relationship between E-cadherin gene mutation and p53 gene mutation, p53 accumulation, Bcl-2 expression and Ki-67 staining in diffuse-type gastric carcinoma. International Journal of Cancer 104, 60-65.

Gama, A., Paredes, J., Milanezi, M.F., Reis-Filho, J.S., Gartner, F., Schmitt, F.C., 2002. P-cadherin expression in canine lactating mammary gland. Journal of Cellular Biochemistry 86, 420-421.

Gama, A., Paredes, J., Albergaria, A., Gartner, F., Schmitt, F.C., 2004. Pcadherin expression in canine mammary tissues. Journal of Comparative Pathology 130, 13-20.

Gamallo, C., Moreno-Bueno, G., Sarrio, D., Calero, F., Hardisson, D., Palacios, J., 2001. The prognostic significance of P-cadherin in infiltrating ductal breast carcinoma. Modern Pathology 14, 650-654.
Gamallo, C., Palacios, J., Suarez, A., Pizarro, A., Navarro, P., Quintanilla, M., 1993. Correlation of E-cadherin expression with differentiation grade and histological grade in breast carcinoma. American Journal of Pathology 142, 987-993.

Gilbertson, S.R., Kurzman, I.D., Zachrau, R.E., Hurvitz, A.I., Black, M.M., 1983. Canine mammary epithelial neoplasms: biologic implications of morphologic characteristics assessed in 232 dogs. Veterinary Pathology 20, 127-142.

Gillet, C.E., Miles, D.W., Ryder, K., Skilton, D., Liebman, R.D., Springall, R.J., Barnes, D.M., Hanby, A.M., 2001. Retention of the expression of E-cadherin and catenins is associated with shorter survival in grade III ductal carcinoma of the breast. Journal of Pathology 193, 433-441.

Gonzalez, M.A., Pinder, S.E., Wencyk, P.M., Bell, J.A., Elston, C.W., Nicholson, R.I., Robertson, J.F., Blamey, R.W., Ellis, I.O., 1999. An immunohistochemical examination of the expression of E-cadherin, $\alpha$ and $\beta / \gamma$-catenins, and $\alpha 2$ - and $\beta 1$-integrins in invasive breast cancer. Journal of Pathology 187, 523-529.

Gumbiner, B.M., 1996. Cell adhesion: the molecular basis of tissue architecture and morphogenesis. Cell 84, 345-357.

Howard, E.M., Lau, S.K., Lyles, R.H., Birdsong, G.G., Umbreit, J.N., Kochhar, R., 2005. Expression of E-cadherin in high-risk breast cancer. Journal of Cancer Research and Clinical Oncology 131, 14-18.

Knudsen, K.A., Frankowski, C., Johnson, K.R., Wheelock, M.J., 1998. A role for cadherins in cellular signaling and differentiation. Journal of Cellular Biochemistry 30-31 (Suppl.), 168-176.

Kovacs, A., Dhillon, J., Walker, R.A., 2003. Expression of P-cadherin, but not E-cadherin or $\mathrm{N}$-cadherin, relates to pathological and functional differentiation of breast carcinomas. Molecular Pathology 56, 318-322.

Madhavan, M., Srinivas, P., Abraham, E., Ahmed, I., Mathew, A., Vijayalekshmi, N.R., Balaram, P., 2001. Cadherins as predictive markers of nodal metastasis in breast cancer. Modern Pathology 14, 423-427.

Matos, A.J.F., Lopes, C., Carvalheira, J., Santos, M., Rutteman, G.R., Gartner, F., 2006. E-cadherin expression in canine malignant mammary tumours: relationship to other clinico-pathological variables. Journal of Comparative Pathology 134, 182-189.

Misdorp, W., Else, R.W., Hellmén, E., Lipscomb, T.P., 1999. Histological Classification of Mammary Tumors of the Dog and the Cat, 2nd series, Vol VII, Armed Forces Institute of Pathology, American Registry of Pathology, Washington D.C. and the World Health Organization Collaborating Center for Worldwide Reference on Comparative Oncology, pp. 1-59.

Misdorp, W., 2002. Tumours of the mammary gland. In: Meuten, D.J. (Ed.), Tumors in Domestic Animals, fourth ed. Iowa State Press, Blackwell Publishing Company, pp. 575-606.

Nose, A., Takeichi, M., 1986. A novel cadherin cell adhesion molecule: its expression patterns associated with implantation and organogenesis of mouse embryos. Journal of Cell Biology 103, 2649-2658.

Palacios, J., Benito, N., Pizarro, A., Suarez, A., Espada, J., Cano, A., Gamallo, C., 1995. Anomalous expression of P-cadherin in breast carcinoma: correlation with E-cadherin expression and pathological features. American Journal of Pathology 146, 605-612.

Paredes, J., Milanezi, F., Viegas, L., Amendoeira, I., Schmitt, F., 2002. Pcadherin expression is associated with high-grade ductal carcinoma in situ of the breast. Virchows Archiv 440, 16-21.

Paredes, J., Stove, C., Stove, V., Milanezi, F., van Marck, V., Derycke, L., Mareel, M., Bracke, M., Schmitt, F., 2004. P-cadherin is up-regulated by the antiestrogen ICI 182,780 and promotes invasion of human breast cancer cells. Cancer Research 64, 8309-8317.

Paredes, J., Albergaria, A., Oliveira, J., Jerónimo, C., Milanezi, F., Schmitt, F., 2005. P-Cadherin overexpression is an Indicator of clinical outcome in invasive breast carcinomas and is associated with $\mathrm{CDH} 3$ promoter hypomethylation. Clinical Cancer Research 11, 5869-5877.

Park, D., Kåresen, R., Axcrona, U., Noren, T., Sauer, T., 2007. Expression pattern of adhesion molecules (E-cadherin, $\alpha-, \beta-, \gamma-$ catenin and claudin-7), their influence on survival in primary breast 
carcinoma, and their corresponding axillary lymph node metastasis. Acta Pathologica, Microbiologica et Immunologica Scandinavica 115, $52-65$.

Peralta Soler, A., Knudsen, K.A., Salazar, H., Han, A.C., Keshgegian, A.A., 1999. P-cadherin expression in breast carcinoma indicates poor survival. Cancer 86, 1263-1272.

Reis, A.L., Carvalheira, J., Schmitt, F.C., Gärtner, F., 2003. Immunohistochemical study of E-cadherin expression in canine mammary tumours. Veterinary Record 152, 621-624.

Restucci, B., Papparella, S., De Vico, G., Maiolino, P., 1997. E cadherin expression in normal and neoplastic canine mammary gland. Journal of Comparative Pathology 116, 191-202.

Shimoyama, Y., Hirohashi, S., Hirano, S., Noguchi, M., Shimosato, Y., Takeichi, M., Abe, O., 1989. Cadherin cell adhesion molecules in human epithelial tissues and carcinomas. Cancer Research 49, 2128 2133.

Siitonen, S.M., Kononen, J.T., Helin, H.J., Rantala, I.S., Holli, K.A., Isola, J.J., 1996. Reduced E-cadherin expression is associated with invasiveness and unfavourable prognosis in breast cancer. American Journal of Clinical Pathology 105, 394-402.
Taniuchi, K., Nakagawa, H., Hosokawa, M., Nakamura, T., Eguchi, H., Ohigashi, H., Ishikawa, O., Katagiri, T., Nakamura, Y., 2005. Overexpressed P-cadherin/CDH3 promotes motility of pancreatic cancer cells by interacting with $\mathrm{p} 120^{\mathrm{ctn}}$ and activating rho-family GTPases. Cancer Research 65, 3092-3099.

Takeichi, M., 1991. Cadherin cell adhesion receptors as a morphogenetic regulator. Science 251, 1451-1455.

Yoshida, R., Kimura, N., Harada, Y., Ohuchi, N., 2001. The loss of Ecadherin, $\alpha$ - and $\beta$-catenin expression is associated with metastasis and poor prognosis in invasive breast cancer. International Journal of Oncology 18, 513-520.

van de Rijn, M., Perou, C.M., Tibshirani, R., Haas, P., Kallioniemi, O., Kononen, J., Torhorst, J., Sauter, G., Zuber, M., Köchli, O.R., Mross, F., Dieterich, H., Seitz, R., Ross, D., Botstein, D., Brown, P., 2002. Expression of cytokeratins 17 and 5 identifies a group of breast carcinomas with poor clinical outcome. American Journal of Pathology 161, 1991-1996.

Wijnhoven, B.P.L., Dinjens, W.N.M., Pignatelli, M., 2000. E-cadherincatenin cell-cell adhesion complex and human cancer. British Journal of Surgery 87, 992-1005. 